\title{
Oral health knowledge, behaviors and parental practices among rural-urban migrant children in Guangzhou: a follow-up study
}

Ning Pan, Li Cai, Caijuan Xu, Han Guan and Yu Jin ${ }^{*}$

\begin{abstract}
Background: Despite the growing number of rural-urban migrant children in China, follow-up observation on the oral health of migrant children is still scarce. This study described the changes of oral health knowledge, behaviors and parental practices in migrant children over a period of one year. Possible factors affecting changes were also investigated.

Methods: The study used purposive sampling to select five private schools of migrant children in Guangzhou. A total of 1900 students in Grades 3 and 4 were recruited. A self-administered questionnaire was used in November 2011 to understand their basic situations, including oral health knowledge, behaviors and parental practices. A final survey was conducted in April 2013 to detect any changes.

Results: The mean accuracy of oral health knowledge was $53.17 \%$ and $59.42 \%$ in 2011 and 2013, respectively $(p<0.001)$. For migrant children, the total score of oral hygiene, dietary habits and parental practices increased at the followup evaluation $(p<0.05)$. Children with less oral health knowledge were more likely to achieve significantly positive changes in score of knowledge $(p<0.001)$ in the final survey. Migrant children who had worse performance on oral hygiene (beta estimate $=0.68, p<0.001$ ), dietary habits (beta estimate $=0.58, p<0.001$ ) and good parental practices in the baseline survey were more likely to obtain beneficial changes. No significant associations between demographic characteristics and changes of oral health knowledge and behaviors $(p>0.05)$ were observed.

Conclusion: Oral health knowledge, behaviors and parental practices among migrant children significantly improved at the follow-up assessment. However, the overall situation was still poor. Positive and effective health education and prevention programs tailored to rural-urban migrant children with varying levels of oral health knowledge, behaviors and parental practices will be needed.
\end{abstract}

Keywords: Migrant children, Oral health, Knowledge, Behaviors, Parental practices

\section{Background}

With the fast economic development, the internal migrant population in China who generally moved from the countryside to the city has grown rapidly. Guangdong Province has become the largest migrant population province, and has an extensive underage migrant population. Guangzhou is the capital of Guangdong Province, and

\footnotetext{
* Correspondence: jinyu@mail.sysu.edu.cn

Department of Maternal and Child Health, School of Public Health, Sun Yat-Sen University, 74 Zhongshan Road 2, Guangzhou, Guangdong 510080, China
}

(c) The Author(s). 2017 Open Access This article is distributed under the terms of the Creative Commons Attribution 4.0 International License (http://creativecommons.org/licenses/by/4.0/, which permits unrestricted use, distribution, and reproduction in any medium, provided you give appropriate credit to the original author(s) and the source, provide a link to the Creative Commons license, and indicate if changes were made. The Creative Commons Public Domain Dedication waiver (http://creativecommons.org/publicdomain/zero/1.0/) applies to the data made available in this article, unless otherwise stated.

represents one of the most developed cities in southern China. According to the 2010 data, the total of 2.738 million migrant children under 14 years old in Guangdong Province accounted for $12.0 \%$ of the national total, and approximately $20 \%$ of the school-age migrant children living in Guangzhou [1]. The government has come to realize the large quantity of migrant children and has embarked on improving their physical and mental health. School-based health education has been implemented, focusing especially on oral health [2]. 
Dental caries is one of the most common preventable childhood diseases and the most common chronic diseases worldwide, which greatly affects the children's general health and quality of life [3]. The caries status in China exhibits characteristics typically found in developing countries $[4,5]$. Specifically, carious teeth are left untreated among $97 \%$ of children aged 5 and $89 \%$ of children aged 12 [6].This situation has barely improved, despite the economic development and oral health-care resource provision [7]. In China, rural children always have a lower level of oral health than urban children [8]. The oral health status among rural-urban migrant children may be even worse considering their relatively poor family economic status, less concern from parents, and limited basic health care. By 2011, the overall caries prevalence among rural-urban migrant children in South China was $85.5 \%$, significantly higher than the averages statistics for both rural and urban areas [9].

Adequate oral health knowledge and parental practices including caries attention and diet guidance are essential to equip children with appropriate oral health behaviors [10-13]. A follow-up investigation is necessary and urgent to society's increased attention to migrant children and the launch of related health planning policies in China [14]. However, information about oral health knowledge, behaviors and parental practices among rural-urban migrant children are still scare. No longitudinal studies on the changes and influencing factors for changes in oral health knowledge and behaviors among migrant children have ever been conducted in China. Therefore, the objectives of the present study were: (1) to describe changes in terms of oral health knowledge, behaviors and parental practices over a period of one year; and (2) to investigate the possible factors influencing the changes of oral health knowledge as well as behaviors, including oral hygiene and dietary habits among migrant children.

\section{Methods}

\section{Study design}

A baseline survey and a follow-up survey were conducted in November 2011 and April 2013 in Guangzhou. We adopted a purposive sampling method, and selected five migrant schools in the Tianhe, Haizhu and Baiyun districts of Guangzhou. This study had obtained permission from headmasters in all participating schools before the survey. Students from all classes of Grades 3 and 4 were recruited from the participating schools as study participants. To ensure that each question was explained similarly to all participants, questionnaires were administered to the whole class during school hours by the same investigator, who were trained and skilled postgraduates. A teacher assisted the administration of the survey to each class. Informed consent forms were sent to the parents of each migrant child prior to the baseline and final surveys, and each parent returned a written consent form.

\section{Study size}

A sample size calculation was established by comparing proportions between the values found in the baseline survey and final survey, using a $90 \%$ power (beta) and $5 \%$ significance (alpha) for calculation. Based on experience from the previous surveys, migrant children were characterized with high mobility and instability. Thus, we hypothesized that the loss rate was $50 \%$. The sample size was estimated to comprise 1051 migrant children. In total, 1900 students were recruited at baseline and 1081 (56.89\%) of them completed the final survey in 2013. The drop-out rate was $43.11 \%$, which was mostly attributed to the high mobility and instability of the migrant population. No differences were found in characteristics (age, sex, family economic status, the baseline scores of oral health knowledge, etc.) between the children who were followed up throughout the study and those who dropped out during the follow-up. A total of 1042 questionnaires remained for analysis, after excluding those ineligible ones.

\section{Data measurement \\ Participant demographics}

Basic demographic information included children's age, grade, gender, number of siblings, age at moving to Guangzhou and family economic status.

\section{Knowledge of oral health scale}

We designed the following 12-item scale to assess migrant children's oral health knowledge. The items included: (1) Eating sweets in the bedtime can lead to cavities; (2) Frequently eating vegetables can lead to cavities; (3) Failure to brush teeth in the morning and evening can cause tooth decay; (4) Irregular arrangement of teeth can cause tooth decay; (5) Hard toothbrush is harmful to teeth; (6) Cavities should be treated in time; (7) Drinking milk is good for tooth development; (8) Cavities will affect the general health; (9) Toothbrushes should be replaced at least every three months. (10) The most important time to brush teeth is during nighttime; (11) Fluoride toothpaste can prevent cavities; and (12) Failure to drink milk can lead to cavities. Two possible responses, true (counted as 1 score) and false (counted as 0 score), were used to answer the above statements, and the possible total scores ranged from 0 to 12 . Higher scores indicated better knowledge regarding oral health (Additional file 1).

\section{Oral hygiene behavior scale for migrant children}

Oral Hygiene Behavior Scale for Migrant Children consisted of five items: (1) "Can each family member have 
their own toothbrush and cup?" (The possible responses and their corresponding scores: sharing toothbrush and cup, sharing toothbrush, sharing cup and yes $=1,2,3$, and 4, respectively); (2) "Which manner are you using to brush your teeth every day?" (casual brushing, horizontal brushing, vertical brushing and vertical brushing with horizontal vibration $=1,2,3$, and 4 , respectively); (3) "How long each time do you brush teeth?" (less than $1 \mathrm{~min}, 1-2 \mathrm{~min}, 2-3 \mathrm{~min}$, and more than $3 \mathrm{~min}=1,2,3$, and 4, respectively); (4) "Do you rinse your mouth after a meal?" (no = 1,yes = 2); and (5) "How many times do you brush teeth each day?"(none, once, twice and three times or more $=1,2,3$ and 4, respectively). These behavioral scores were summed, and the total score range was 5-18. Children who obtained higher scores had better oral hygiene behaviors (Additional file 1).

\section{Dietary habit scale for migrant children}

Five items were included in the Dietary Habit Scale for Migrant Children: (1) "How often do you eat chocolate pie or cream cake?"; (2) "How often do you drink carbonated beverages?"; (3) "How often do you eat cheese?"; (4) "How often do you eat candy?" and (5) "How often do you eat ice cream or butter?" Possible responses included "always, sometimes, or rarely", and these answers scored " 1,2 , or 3 ", respectively. The total score range was $5-15$. The higher scores indicated better dietary habits (Additional file 1).

\section{Parental practices scale for migrant children}

Six questions regarding parental practices of migrant children, including parental caries attention (two items) and parental diet guidance (four items), were designed by Sun Yat-sen University School of Public Health. The scale of parental caries attention was measured on a 3point Likert scale with ratings from 1 to 3 . The scale of parental diet guidance was measured on a 5-point Likert scale with ratings from 1 (rarely) to 5 (always). The question of "Do your parents often give you money for snacks?" used reverse scoring. Cumulative scores were summed for each scale, with higher scores reflecting more positive parental practices (Additional file 1).

\section{Statistical analysis}

EpiData 3.0 was used for data entry and SPSS 19.0 was used to for data analysis. Descriptive statistics was used to show the participants' demographics and the chisquare test was applied to evaluate differences according to gender. A paired sample test was performed to analyze the total score and the accuracy of oral health knowledge in rural-urban migrant children. The marginal homogeneity tests compared the changes between the 2011 and 2013 surveys on oral behaviors and parental practices of migrant children. All items were ranked from the most beneficial to the least beneficial change. Ordinal logistic regression assessed the presence and degree of association of independent variables, including participant demographics and the baseline score of oral health knowledge, behaviors and parental practices, with the changes. The changes were grouped into three categories by the difference between the scores of the two surveys. Those with the difference $<0,=0$, and $>0$ were classified to have worst changes, no changes and beneficial changes, respectively. A $\mathrm{p}$ value $<0.05$ indicated a statistically significant difference.

\section{Results}

Demographic distribution of migrant children in five private primary schools

Table 1 shows the demographic information of the 1042 migrant children in the baseline survey. For migrant children, the average age was $9.56 \pm 1.00$ and the gender ratio was 1.33:1 (boys: girls), respectively. The majority had one or more siblings (90.60\%). More than half of the migrant children were born in Guangdong Province. Furthermore, $72.08 \%$ of the floating children had moved to Guangzhou before they went to the primary school (under six years old), and $65.36 \%$ of families were in median or poor economic status. With regard to gender differences, more boys came from other provinces, and girls were more likely to have good living conditions.

\section{Accuracy of oral health knowledge of migrant children in} 2011 and 2013

The mean accuracy of oral health knowledge in 2013 in migrant children was $59.42 \%$, which was higher than that in the 2011 survey $(53.17 \% ; p<0.001)$. Table 2 shows a comparison of the accuracy of each item between two surveys, which ranged from 16.22 to $82.05 \%$ in 2011 and from 13.05 to $90.79 \%$ in 2013 . Over a oneyear period, the item, "Eating sweets in the bedtimes can lead to cavities," received the most beneficial change.

Only about one-fifth of the sample realized that milk is good for dental health $(n=222 ; 21.31 \%)$ and that cavities should be treated in time $(n=236 ; 22.65 \%)$; these data were different from the data in the 2011 survey ( $n=169 ; 16.22 \%$ and $n=172 ; 16.51 \%$, respectively). Approximately, $32 \%$ of respondents knew that toothbrushes should be replaced at least every three months, which was also different from the previous survey results $(n=289 ; 27.74 \%)$. The accuracy of the items "Fluoride toothpaste can prevent cavities" and "Failure to drink milk can lead to cavities" decreased in the 2013 survey $(p<0.001)$. Additionally, no difference in the item "The most important time to brush teeth is during nighttime" was found. Regarding most of the knowledge items, the correct rates in 2013 were significantly higher than those in 2011. 
Table 1 Demographic distribution of migrant children in the baseline survey in 2011

\begin{tabular}{|c|c|c|c|c|}
\hline & Total & Boys & Girls & $p$-value \\
\hline & $n(\%)^{\mathrm{b}}$ & $n(\%)^{b}$ & $n(\%)^{\mathrm{b}}$ & \\
\hline Sample size & $1042(100)$ & $594(57.01)$ & $448(42.99)$ & \\
\hline Age (year), mean $\pm s d$ & $9.56 \pm 1.00$ & $9.67 \pm 1.02$ & $9.41 \pm 0.94$ & $<0.001$ \\
\hline Grade & & & & 0.067 \\
\hline 3 & $501(48.08)$ & $271(45.62)$ & $230(51.34)$ & \\
\hline 4 & $541(51.92)$ & $323(54.38)$ & $218(48.66)$ & \\
\hline Siblings & & & & 0.398 \\
\hline 0 & $98(9.40)$ & $62(10.44)$ & $36(8.03)$ & \\
\hline $1-2$ & $590(56.62)$ & $330(55.55)$ & $260(58.04)$ & \\
\hline 3 or more & $354(33.98)$ & $202(34.01)$ & $152(33.93)$ & \\
\hline Place of birth & & & & 0.037 \\
\hline Guangdong Province & $559(53.65)$ & $302(50.84)$ & $257(57.37)$ & \\
\hline Other Province & $483(46.35)$ & $292(49.16)$ & $191(42.63)$ & \\
\hline Age at moving to Guangzhou & & & & 0.055 \\
\hline $0 \sim 3$ & $413(39.64)$ & $228(38.38)$ & $185(41.29)$ & \\
\hline $3 \sim 6$ & $338(32.44)$ & $183(30.81)$ & $155(34.60)$ & \\
\hline 6 and above & $291(27.92)$ & $183(30.81)$ & $108(24.11)$ & \\
\hline Family economic status & & & & 0.007 \\
\hline Good & $361(34.64)$ & $182(30.64)$ & 179 (39.96) & \\
\hline Median & 555 (53.26) & $335(56.40)$ & $220(49.11)$ & \\
\hline Poor & $126(12.10)$ & 77 (12.96) & 49 (10.93) & \\
\hline
\end{tabular}

${ }^{\text {a }}$ Statistical evaluation using chi-square tests for differences according to gender

${ }^{\mathrm{b}}$ All data are expressed as $\mathrm{n}(\%)$ unless otherwise stated

\section{Oral health behaviors of migrant children in 2011 and 2013}

Responses to selected questions about oral health behaviors, including oral hygiene and dietary habits, are shown in Table 3. The percentage of migrant families who had their own toothbrush and cup increased from 56.14 to $67.37 \%$ in one year. In the baseline survey,
$44.72 \%$ of migrant children were found to brush their teeth incorrectly, using methods such as horizontal brushing, vertical brushing, and casual brushing. However, one year later, the proportion dropped to $33.88 \%$. Nearly half of the migrant children $(n=513 ; 49.23 \%)$ brushed their teeth for less than two minutes per time in 2011; this number was higher than that in $2013(n=455$;

Table 2 The accuracy of caries-related knowledge of rural-urban migrant children $(n=1042)$

\begin{tabular}{|c|c|c|c|c|}
\hline & $2011(\%)$ & 2013(\%) & Change (\%) & $p$-value $e^{a}$ \\
\hline Eating sweets in the bedtimes can lead to cavities & 69.67 & 89.73 & 20.06 & $<0.001$ \\
\hline Frequently eating vegetables can lead to cavities & 71.59 & 90.79 & 19.20 & $<0.001$ \\
\hline Failure to brush teeth in the morning and evening can cause tooth decay & 70.44 & 88.96 & 18.52 & $<0.001$ \\
\hline Irregular arrangement of teeth can cause tooth decay & 77.06 & 88.58 & 11.52 & $<0.001$ \\
\hline Hard toothbrush is harmful to teeth & 82.05 & 88.68 & 6.63 & $<0.001$ \\
\hline Cavities should be treated in time & 16.51 & 22.65 & 6.14 & $<0.001$ \\
\hline Drinking milk is good for tooth development & 16.22 & 21.31 & 5.09 & 0.002 \\
\hline Cavities will affect the general health & 75.82 & 80.52 & 4.70 & 0.009 \\
\hline Toothbrushes should be replaced at least every three months & 27.74 & 32.15 & 4.41 & 0.019 \\
\hline The most important time to brush teeth is during nighttime & 28.02 & 25.34 & -2.68 & 0.123 \\
\hline Fluoride toothpaste can prevent cavities & 78.98 & 71.50 & -7.48 & $<0.001$ \\
\hline Failure to drink milk can lead to cavities & 23.61 & 13.05 & -10.56 & $<0.001$ \\
\hline
\end{tabular}


Table 3 Oral hygiene and dietary habits among migrant children in 2011 and 2013 ( $n=1042)$

\begin{tabular}{|c|c|c|c|c|}
\hline & $2011(\bar{x} \pm s)$ & $2013(\bar{x} \pm s)$ & Change $(\bar{x} \pm s)$ & $p$-value ${ }^{a}$ \\
\hline \multicolumn{5}{|l|}{ Oral hygiene } \\
\hline Total score & $13.98 \pm 2.25$ & $14.30 \pm 2.19$ & $0.32 \pm 2.72$ & $<0.001$ \\
\hline Can each family member have their own toothbrush and cup? & $3.37 \pm 0.87$ & $3.58 \pm 0.71$ & $0.21 \pm 1.02$ & $<0.001$ \\
\hline Yes & $56.14 \%$ & $67.37 \%$ & & \\
\hline Sharing cup & $31.48 \%$ & $26.30 \%$ & & \\
\hline Sharing toothbrush & $5.66 \%$ & $3.07 \%$ & & \\
\hline Sharing toothbrush and cup & $6.72 \%$ & $3.26 \%$ & & \\
\hline Which manner are you using to brush your teeth every day? & $3.09 \pm 1.13$ & $3.29 \pm 1.09$ & $0.20 \pm 1.42$ & $<0.001$ \\
\hline Casual brushing & $13.82 \%$ & $11.90 \%$ & & \\
\hline Vertical brushing & $12.48 \%$ & $8.64 \%$ & & \\
\hline Horizontal brushing & $18.42 \%$ & $13.34 \%$ & & \\
\hline Vertical brushing with horizontal vibration & $55.28 \%$ & $66.12 \%$ & & \\
\hline How long each time do you brush your teeth? & $2.57 \pm 0.97$ & $2.68 \pm 0.92$ & $0.11 \pm 1.21$ & 0.004 \\
\hline Less than one minute & $14.59 \%$ & $9.88 \%$ & & \\
\hline $1-2$ minutes & $34.64 \%$ & $33.78 \%$ & & \\
\hline 2-3 minutes & $30.23 \%$ & $35.12 \%$ & & \\
\hline More than three minutes & $20.54 \%$ & $21.22 \%$ & & \\
\hline Do you rinse your mouth after a meal? & $1.56 \pm 0.50$ & $1.59 \pm 0.49$ & $0.02 \pm 0.62$ & 0.213 \\
\hline Yes & $56.33 \%$ & $58.73 \%$ & & \\
\hline No & $43.67 \%$ & $41.27 \%$ & & \\
\hline How many times do you brush teeth each day? & $3.38 \pm 0.78$ & $3.17 \pm 0.76$ & $-0.21 \pm 1.01$ & $<0.001$ \\
\hline None & $1.63 \%$ & $0.78 \%$ & & \\
\hline Once & $13.44 \%$ & $19.58 \%$ & & \\
\hline Twice & $29.94 \%$ & $41.94 \%$ & & \\
\hline Three times or more & $54.99 \%$ & $38.00 \%$ & & \\
\hline \multicolumn{5}{|l|}{ Dietary habits } \\
\hline Total score & $10.33 \pm 2.33$ & $10.61 \pm 2.15$ & $0.28 \pm 2.62$ & 0.001 \\
\hline How often do you eat chocolate pie or cream cake? & $1.96 \pm 0.74$ & $2.08 \pm 0.66$ & $0.12 \pm 0.91$ & $<0.001$ \\
\hline Always eat & $29.27 \%$ & $18.33 \%$ & & \\
\hline Sometimes eat & $45.59 \%$ & $55.66 \%$ & & \\
\hline Rarely eat & $25.14 \%$ & $26.01 \%$ & & \\
\hline How often do you eat carbonated beverage? & $2.00 \pm 0.73$ & $2.10 \pm 0.65$ & $0.10 \pm 0.84$ & $<0.001$ \\
\hline Always eat & $26.58 \%$ & $16.31 \%$ & & \\
\hline Sometimes eat & $47.22 \%$ & $57.39 \%$ & & \\
\hline Rarely eat & $26.20 \%$ & $26.30 \%$ & & \\
\hline How often do you eat cheese? & $2.19 \pm 0.73$ & $2.25 \pm 0.72$ & $0.06 \pm 0.92$ & 0.026 \\
\hline Always eat & $19.19 \%$ & $16.22 \%$ & & \\
\hline Sometimes eat & $43.09 \%$ & $42.71 \%$ & & \\
\hline Rarely eat & $37.72 \%$ & $41.07 \%$ & & \\
\hline How often do you eat candy? & $2.16 \pm 0.71$ & $2.20 \pm 0.63$ & $0.04 \pm 0.84$ & 0.113 \\
\hline Always eat & $18.81 \%$ & $11.90 \%$ & & \\
\hline Sometimes eat & $46.55 \%$ & $56.24 \%$ & & \\
\hline Rarely eat & $34.64 \%$ & $31.86 \%$ & & \\
\hline
\end{tabular}


Table 3 Oral hygiene and dietary habits among migrant children in 2011 and 2013 ( $n=1042)$ (Continued)

\begin{tabular}{llll}
\hline How often do you eat ice cream or butter? & $2.03 \pm 0.72$ & $1.98 \pm 0.68$ & $-0.05 \pm 0.90$ \\
Always eat & $24.57 \%$ & $24.09 \%$ & 0.106 \\
Sometimes eat & $48.18 \%$ & $53.65 \%$ & \\
Rarely eat & $27.25 \%$ & $22.26 \%$ & \\
\hline
\end{tabular}

${ }^{a}$ Marginal Homogeneity Test

43.66\%). The majority of respondents gargled after a meal $(n=403 ; 41.27 \%)$, which was not significantly different from the results of the 2011 survey $(n=455$; 43.67\%). Almost a fifth of the migrant children $(n=212$; $20.36 \%$ ) brushed their teeth less than once per day, which differed from the results of the 2011 survey $(n=$ $157 ; 15.07 \%)$.

With respect to dietary habits of migrant children, the numbers (percentages) of children who always consumed sweet foods in 2013 were as follows: 191 (18.33\%) for chocolate pie or cream cake, 170 (16.31\%) for carbonated beverage, 169 (16.22\%) for cheese, 124 (11.90\%) for candy, and 251 (24.09\%) for ice cream or butter. The frequency of eating chocolate pie or cream cake, carbonated beverage and cheese significantly decreased since the 2011 survey $(p<0.05)$.

\section{Parental practices among migrant children in 2011 and 2013}

Table 4 reveals responses to questions on parental practices, including attention to children's caries and diet guidance. Approximately $17.66 \%$ of migrant children indicated that their parents rarely paid attention to their teeth, which was different from the 2011 survey $(n=$ $271 ; 26.01 \%)$. Additionally, $34.84 \%$ of parents dealt with their children's toothache and caries with a negative attitude. A year later, the proportion was still $30.71 \%$. The mean score of parental attention was $4.67 \pm 1.13$ and $4.84 \pm 1.05$, with a significant difference observed between two years $(p<0.05)$.

No significant changes were observed in parental diet guidance, including informing and supervising what their children buy and eat. Nearly $67.47 \%$ of parents sometimes or rarely gave their children money for snacks; this number was higher than that in $2011(n=$ $601 ; 57.68 \%)$. The mean score of migrant children's parental diet guidance was $12.02 \pm 3.14$ and $12.29 \pm 3.43$, with a significant difference observed between the two years $(p<0.05)$.

\section{Factors for changes of oral health knowledge, behaviors and dietary habits among migrant children}

The results of ordinal logistic regression are presented in Table 5. All models presented a good fit $(p<0.001)$ : The parallel line test could not reject the null hypothesis $(p>0.05)$ and the Pearson chi-square goodness-of-fit measure was always non-significant. These summary measures suggested satisfactory ordinal logistic regression models [15].

The children with less oral health knowledge in the baseline were more likely to achieve significantly positive changes in their knowledge score $(p<0.001)$ in the final survey. Migrant children who had worse performance on oral hygiene (beta estimate $=0.68, p<0.001$ ) and a higher frequency of consuming sugar-containing food (beta estimate $=0.58, p<0.001$ ) in the baseline survey were more likely to obtain beneficial changes. Regarding parental practices, children whose parents paid more attention to children's caries (beta estimate $=-0.19, p=$ $0.003)$ and gave children more reasonable dietary guidance (beta estimate $=-0.06, p=0.012$ ) were more likely to receive beneficial changes in oral hygiene after one year. Meanwhile, children with parents who gave reasonable dietary guidance were less likely to frequently consume sugar-containing food (beta estimate $=-0.06$, $p=0.007)$ in 2013. No significant associations between demographic characteristics and changes in oral health knowledge and behaviors $(p>0.05)$ were observed.

\section{Discussion}

Limited data are available to analyze and supervise oral health knowledge, behaviors and parental practices among rural-urban migrant children in China. In general, the situation of oral health knowledge, behaviors and parental practices among migrant children significantly improved during the study, but the overall level was still poor at the follow-up evaluation. Our results showed that oral health knowledge, behaviors and parental practices in the baseline survey were associated with changes of oral health knowledge and behaviors (including oral hygiene and dietary habits) one year later. Migrant children with less oral health knowledge and worse performance on oral behaviors in the baseline were more likely to achieve significantly positive changes. Our findings also confirmed that parental attention to caries and reasonable dietary guidance were related to beneficial changes in the final survey.

The average awareness rate of oral health knowledge was $53.17 \%$ among migrant children in the 2011 survey. However, limited studies regarding the level of oral health knowledge of migrant children in China are available. Most previous studies explored the difference 
Table 4 Parental practices among migrant children in 2011 and $2013(n=1042)$

\begin{tabular}{|c|c|c|c|c|}
\hline & $2011(\bar{x} \pm s)$ & $2013(\bar{x} \pm s)$ & Change $(\bar{x} \pm s)$ & $p$-value $e^{a}$ \\
\hline \multicolumn{5}{|l|}{ Parental attention to children's caries } \\
\hline Total score & $4.67 \pm 1.13$ & $4.84 \pm 1.05$ & $0.17 \pm 1.31$ & $<0.001$ \\
\hline Will your parents always pay attention to whether you have caries? & $2.14 \pm 0.80$ & $2.23 \pm 0.73$ & $0.09 \pm 0.95$ & 0.002 \\
\hline Always & $39.64 \%$ & $40.69 \%$ & & \\
\hline Sometimes & $34.35 \%$ & $41.65 \%$ & & \\
\hline Rarely & $26.01 \%$ & $17.66 \%$ & & \\
\hline $\begin{array}{l}\text { If you have pain with your teeth or have caries, which of the following } \\
\text { measures will your parents take? }\end{array}$ & $2.53 \pm 0.70$ & $2.61 \pm 0.64$ & $0.08 \pm 0.86$ & 0.003 \\
\hline Take you to the hospital and follow the doctor's recommendations & $65.16 \%$ & $69.29 \%$ & & \\
\hline Left unchecked, or be ignored & $12.09 \%$ & $8.25 \%$ & & \\
\hline Depending on the state & $22.75 \%$ & $22.46 \%$ & & \\
\hline \multicolumn{5}{|l|}{ Parental diet guidance } \\
\hline Total score & $12.02 \pm 3.14$ & $12.29 \pm 3.43$ & $0.27 \pm 4.01$ & 0.032 \\
\hline Do your parents often give you money for snacks? & $3.67 \pm 1.10$ & $3.80 \pm 1.10$ & $0.13 \pm 1.34$ & 0.002 \\
\hline Always & $3.74 \%$ & $4.80 \%$ & & \\
\hline Usually & $10.65 \%$ & $7.58 \%$ & & \\
\hline Often & $27.93 \%$ & $20.15 \%$ & & \\
\hline Sometimes & $29.94 \%$ & $37.43 \%$ & & \\
\hline Rarely & $27.74 \%$ & $30.04 \%$ & & \\
\hline When your parents give you money, do they tell you what to buy? & $2.54 \pm 1.38$ & $2.64 \pm 1.52$ & $0.10 \pm 1.93$ & 0.092 \\
\hline Always & $11.42 \%$ & $18.62 \%$ & & \\
\hline Usually & $14.78 \%$ & $13.05 \%$ & & \\
\hline Often & $23.61 \%$ & $16.79 \%$ & & \\
\hline Sometimes & $16.99 \%$ & $17.08 \%$ & & \\
\hline Rarely & $33.20 \%$ & $34.46 \%$ & & \\
\hline Do your parents often supervise what kind of snacks you buy? & $2.68 \pm 1.43$ & $2.71 \pm 1.53$ & $0.04 \pm 1.91$ & 0.538 \\
\hline Always & $15.36 \%$ & $20.35 \%$ & & \\
\hline Usually & $15.16 \%$ & $13.63 \%$ & & \\
\hline Often & $21.88 \%$ & $15.16 \%$ & & \\
\hline Sometimes & $16.99 \%$ & $18.71 \%$ & & \\
\hline Rarely & $30.61 \%$ & $32.15 \%$ & & \\
\hline Do you often discuss how to eat is a healthy diet at home with your parents? & $3.13 \pm 1.36$ & $3.13 \pm 1.39$ & $0.00 \pm 1.77$ & 0.986 \\
\hline Always & $21.02 \%$ & $22.46 \%$ & & \\
\hline Usually & $20.44 \%$ & $20.44 \%$ & & \\
\hline Often & $25.91 \%$ & $21.11 \%$ & & \\
\hline Sometimes & $16.12 \%$ & $19.87 \%$ & & \\
\hline Rarely & $16.51 \%$ & $16.12 \%$ & & \\
\hline
\end{tabular}

${ }^{\text {a Marginal Homogeneity Test }}$

between children in urban and rural areas $[8,14]$. Compared with previous studies, the level of oral health knowledge among migrant children in Guangzhou is not optimistic. For example, $70.44 \%$ children knew that brushing teeth can protect from dental decay while the corresponding percentage in Ethiopia was 85\% [16]. Only $27.74 \%$ had accurate knowledge on the importance of replacing the toothbrush at least every three months, which was lower than the rate in Nepal [17]. A total of $75.82 \%$ of the respondents were aware that dental caries can affect general health, whereas only $16.51 \%$ understood that cavities should be treated in time. The level of oral health knowledge increased significantly since the survey in 2011. The reason for the improvement may be related 
Table 5 Ordinal logistic regression analysis for changes of oral health knowledge, oral hygiene and dietary habits

\begin{tabular}{|c|c|c|c|c|c|c|c|c|c|}
\hline \multirow[b]{2}{*}{ Variables } & \multicolumn{3}{|c|}{ Change of oral health knowledge } & \multicolumn{3}{|c|}{ Change of oral hygiene ${ }^{b}$} & \multicolumn{3}{|c|}{ Change of dietary habits ${ }^{c}$} \\
\hline & $\begin{array}{l}\text { Regression } \\
\text { coefficient }\end{array}$ & $p$-value & OR $(95 \% \mathrm{Cl})$ & $\begin{array}{l}\text { Regression } \\
\text { coefficient }\end{array}$ & $p$-value & OR $(95 \% \mathrm{Cl})$ & $\begin{array}{l}\text { Regression } \\
\text { coefficient }\end{array}$ & $p$-value & OR $(95 \% \mathrm{Cl})$ \\
\hline Intercept $_{1}$ (Beneficial change) & 3.93 & 0.001 & . & 7.83 & $<0.001$ & . & 5.37 & $<0.001$ & . \\
\hline Intercept $t_{2}$ (No change) & 5.04 & $<0.001$ & & 8.65 & $<0.001$ & . & 6.32 & $<0.001$ & . \\
\hline Age (year) & -0.06 & 0.475 & $0.94(0.79,1.12)$ & -0.05 & 0.555 & $0.95(0.81,1.12)$ & 0.03 & 0.758 & $1.03(0.87,1.21)$ \\
\hline \multicolumn{10}{|l|}{ Gender } \\
\hline Boy & 0.07 & 0.610 & $1.08(0.81,1.42)$ & 0.09 & 0.502 & $1.10(0.84,1.44)$ & 0.09 & 0.512 & $1.09(0.84,1.42)$ \\
\hline Girl & Reference & . & . & Reference & . & . & Reference & & . \\
\hline \multicolumn{10}{|l|}{ Grade } \\
\hline 3 & -0.11 & 0.518 & $0.89(0.64,1.26)$ & -0.02 & 0.909 & $0.98(0.70,1.36)$ & 0.16 & 0.341 & $1.17(0.85,1.61)$ \\
\hline 4 & Reference & & . & Reference & & . & Reference & . & . \\
\hline \multicolumn{10}{|l|}{ Age at moving to Guangzhou } \\
\hline $0 \sim 3$ & 0.17 & 0.353 & $1.18(0.83,1.67)$ & -0.10 & 0.546 & $0.90(0.65,1.26)$ & -0.26 & 0.113 & $0.77(0.55,1.06)$ \\
\hline $3 \sim 6$ & 0.10 & 0.570 & $1.11(0.78,1.58)$ & -0.01 & 0.968 & $0.99(0.70,1.40)$ & 0.04 & 0.815 & $1.04(0.75,1.45)$ \\
\hline 6 and above & Reference & & . & Reference & e & . & Reference & . & . \\
\hline \multicolumn{10}{|l|}{ Siblings } \\
\hline 0 & -0.05 & 0.845 & $0.95(0.58,1.56)$ & -0.30 & 0.235 & $0.74(0.45,1.21)$ & -0.21 & 0.382 & $0.81(0.50,1.30)$ \\
\hline $1-2$ & 0.10 & 0.526 & $1.10(0.82,1.47)$ & -0.02 & 0.880 & $0.98(0.73,1.30)$ & 0.01 & 0.926 & $1.01(0.77,1.34)$ \\
\hline 3or more & Reference & & . & Reference & . & . & Reference & . & . \\
\hline \multicolumn{10}{|l|}{ Family economic status } \\
\hline Good & -0.04 & 0.862 & $0.96(0.60,1.54)$ & -0.21 & 0.381 & $0.81(0.51,1.29)$ & 0.34 & 0.145 & $1.40(0.89,2.21)$ \\
\hline Median & -0.19 & 0.421 & $0.83(0.53,1.31)$ & 0.22 & 0.342 & $1.24(0.80,1.93)$ & 0.12 & 0.590 & $1.13(0.73,1.74)$ \\
\hline Poor & Reference & & . & Reference & & . & Reference & . & . \\
\hline \multicolumn{10}{|l|}{ Place of birth } \\
\hline Other Province & 0.09 & 0.537 & $1.09(0.83,1.44)$ & 0.15 & 0.285 & $1.16(0.88,1.52)$ & 0.14 & 0.300 & $1.15(0.88,1.49)$ \\
\hline Guangdong Province & Reference & . & . & Reference & . & . & Reference & & . \\
\hline \multicolumn{10}{|l|}{ Oral health knowledge } \\
\hline Baseline score & 0.96 & $<0.001$ & $2.61(2.33,2.93)$ & -0.01 & 0.888 & $0.99(0.92,1.07)$ & -0.02 & 0.597 & $0.98(0.91,1.05)$ \\
\hline \multicolumn{10}{|l|}{ Oral health behaviors } \\
\hline Baseline score of oral hygiene & -0.06 & 0.097 & $0.95(0.88,1.01)$ & 0.68 & $<0.001$ & $1.96(1.81,2.13)$ & 0.02 & 0.556 & $1.02(0.96,1.08)$ \\
\hline Baseline score of dietary habits & -0.04 & 0.189 & $0.96(0.91,1.02)$ & 0.05 & 0.103 & $1.05(0.99,1.11)$ & 0.58 & $<0.001$ & $1.79(1.66,1.92)$ \\
\hline \multicolumn{10}{|l|}{ Parental practices } \\
\hline $\begin{array}{l}\text { Baseline score of attention to } \\
\text { children's caries }\end{array}$ & -0.09 & 0.181 & $0.92(0.81,1.04)$ & -0.19 & 0.003 & $0.82(0.73,0.93)$ & -0.07 & 0.264 & $0.93(0.83,1.05)$ \\
\hline Baseline score of dietary guidance & -0.04 & 0.090 & $0.96(0.92,1.01)$ & -0.06 & 0.012 & $0.95(0.91,0.99)$ & -0.06 & 0.007 & $0.94(0.90,0.98)$ \\
\hline
\end{tabular}

${ }^{\mathrm{a}}$ Model fitting information: chi-square $=445.63(p<0.001)$; Test of parallel lines: chi-square $=11.81(p=0.694)$; Goodness-of-fit: (i) Pearson chi-square $=2133.98$ $(p=0.149)$ and (ii) Deviance chi-square $=1618.62(p=1.00)$

${ }^{\mathrm{b}}$ Model fitting information: chi-square $=403.54(p<0.001)$; Test of parallel lines: chi-square $=17.88(p=0.269)$; Goodness-of-fit: (i) Pearson chi-square $=2007.26$ $(p=0.823)$ and (ii) Deviance chi-square $=1678.33(p=1.00)$

${ }^{c}$ Model fitting information: chi-square $=364.76(p<0.001)$; Test of parallel lines: chi-square $=11.50(p=0.716)$; Goodness-of-fit: (i) Pearson chi-square $=2096.30$ $(p=0.321)$ and (ii) Deviance chi-square $=1780.32(p=1.00)$

to the existing school-based oral health education programs conducted by the government in Guangzhou, such as teacher training, oral health lectures and knowledge competitions. However, the correct rate of the following two questions, "Fluoride toothpaste can prevent cavities," and "Failure to drink milk can lead to cavities," decreased significantly. This finding suggests that certain sorts of knowledge (e.g. the above two) may be less emphasized or even ignored in the current health education programs. A more comprehensive design for health education programs from the government and school is needed to promote the oral health knowledge of migrant children. 
Given the lack of oral health knowledge, the majority of migrant children in our study had unhealthy oral behaviors. Approximately $15.07 \%$ of migrant children in the baseline survey reported that they brushed their teeth once a day or had never cleaned their teeth over the last month. Nearly half of the respondents brushed their teeth in an incorrect manner and for less than two minutes only. About $43.86 \%$ of children shared brushing tools with their family members. These proportions of unhealthy oral behaviors were higher than those found in central and northern China $[13,18]$ and several other developing countries $[17,19,20]$. The findings may result from poor oral health knowledge among migrant children and insufficient concern from their parents. Over a period of one year, albeit not always statistically significantly, most of oral hygiene behaviors achieved beneficial changes. Migrant children tended to improve the most in their performance on sharing brushing tools with family members, but the least in frequent brushing. Regular and frequent brushing shall be promoted, considering that brushing is the most common and effective method to mechanically remove plaque and white scale [21], and that brushing teeth at least twice a day can more effectively remove plaque and maintain oral hygiene [22]. Overall, oral health education programs should focus on teaching migrant children to brush regularly and correctly and not to share brushing tools with others. Regarding the dietary habits of migrant children, the frequency of consuming sweet-containing food was lower than that of urban children in China [13] and several other developed countries [23]. Moreover, the frequency of consuming chocolate pie or cream cake, carbonated beverage and cheese tended to decrease significantly in the 2013 survey. These findings might be partly explained by the low income among migrant families, who were limited in their financial capabilities to purchase sugar and snacks. To some extent, these situations can help maintain and promote oral health in migrant children.

Previous studies illustrated that the practices of caregivers could influence the health behaviors of their cared $[13,24]$. This study showed that the parental practices towards their migrant children, including attention to their children's caries and dietary guidance, were relatively negative. Only $39.64 \%$ of parents were always concerned with the oral health of their children. Nearly a third of parents preferred to ignore children's toothache and caries development. The dental caries of migrant children did not receive prompt treatment, similar to the situation in most developing countries $[17,25,26]$. This situation had improved in 2013 but was still unsatisfied. These results could be partly explained by the poor economic condition, the lack of medical resources, and the social and cultural isolation of migrant children's parents. Given the intense life and work pressures, communication between parents and their migrant children is less effective than that of local residents, which reduces the influence of parents on children's health behaviors [27]. With regard to diet, low income allows only $3.74 \%$ of migrant parents to always give their children money for snacks, which to some extent prevents the incidence of unhealthy dietary habits. However, only $11.42 \%$ and $15.36 \%$ of the parents always supervised the purchase choices of their children. These findings indicated that fewer migrant parents could provide their children with reasonable diet guidance, and such situation did not significantly improve in the finial survey. It is thus recommended that the future health education programs should cover relevant workshops or lectures to improve the migrant parental practices regarding dental health.

Oral health knowledge and behaviors are influenced by many factors. This study shows that the level of oral health knowledge, behaviors and parental practices at the baseline significantly affected the changes of the oral health knowledge, oral hygiene and dietary habits of migrant children in the final survey. The association between oral health knowledge and oral behaviors has also been confirmed in many other studies [28-30]. In the present study, our findings suggest that children with less oral health knowledge were more likely to achieve significantly positive changes one year later. Thus, health education programs should target the different between migrant children with various levels of oral health knowledge, and the dental health curriculum content should be designed depending on the children's current oral health knowledge. Additionally, we found that migrant children who had a relatively worse performance on oral health behaviors and dietary habits tended to increase their oral hygiene behaviors and to consume sugary food rarely. These findings suggest that school-based dental health programs should pay particular attention to the children with worse oral hygiene and dietary habits, because they are more likely to achieve beneficial changes. Significant associations between the changes of oral behaviors and parental practices were observed; this finding correlates with other studies reporting that parental oral behaviors and attitudes are related with the oral health of children [26, 31, 32]. Migrant children with less parental attention and unreasonable dietary guidance were less likely to achieve beneficial changes in the final survey, indicating that increasing parental practices could positively influence the oral behaviors and dietary habits of migrant children. However, the status quo is that migrant children always experience ineffective communication with parents who are often busy working and confronted with poor living conditions. Migrant children and their parents should both take part in 
health education programs by strengthening the communication in family members to raise oral health knowledge and promote healthy oral behaviors.

Limitations of this study should be noted. First, five migrant children's schools were selected by purposive sampling owing to the instability and overcrowding of migrant children. Despite the limitation of sampling, our communication with the local administration and education organizations suggest that the five schools are typical migrant schools in terms of tuition fee, geographic location, and students' demographic and socioeconomic profiles. Second, the oral health-related behaviors were self-reported, which might be subject to recall bias. Third, a high follow-up loss, which was mostly attributed to the high mobility and instability of the migrant population, was observed. However, no significant differences were found in characteristics (age, sex, family economic status, the baseline scores of oral health knowledge, etc.) between the children who were followed up throughout the study and those who dropped out during the follow-up.

\section{Conclusion}

This study shows that oral health knowledge, behaviors and parental practices among migrant children are significantly improved during a one-year follow-up period; however, the overall situation has remained poor until the end of follow up. The baseline oral health knowledge, behaviors and parental practices is likely to affect the changes of oral health knowledge and behaviors (including oral hygiene and dietary habits). We speculate that the existing school-based health program may be beneficial to the improvement, and thus recommend the government to improve the basic health education system. The future health education system could consider to provide targeted or personalized education programs to the different migrant populations with various levels of oral health knowledge, behaviors and parental practices, and to provide comprehensive oral education programs targeting both children and their caregivers. The oral health of migrants in China requires focused attention and further improvement in the future.

\section{Additional file}

Additional file 1: Questionnaire of Oral Health. We design this questionnaire of oral health to investigate oral health knowledge, behaviors and parental practices among rural-urban migrant children. The same questionnaire was sent to children in the baseline and final survey. (DOC $78 \mathrm{~kb}$ )

\section{Acknowledgements}

The study was supported by the Guangzhou Women's Federation. The authors appreciate the support of the participating school and the assistance of the school teachers and the staff members.
Funding

The study was supported by the Guangzhou Women's Federation.

\section{Availability of data and materials}

We'd like not to share our raw data in the manuscript, because the raw data is being applied to another unpublished article and the project group has not published the data in whole elsewhere.

\section{Authors' contributions}

$N P$ is the primary writer of the manuscript. YJ designed the study and helped to draft the manuscript. LC revised the manuscript. NP and CX performed statistical analysis. HG participated in administering the questionnaire. All authors read and approved the final manuscript.

\section{Competing interests}

The authors declare that they have no competing interests.

\section{Consent for publication}

Not applicable.

\section{Ethics approval and consent to participate}

Approval for this study was obtained from the Ethics Committee on Research of Human Subjects at Sun Yat-sen University. Prior to the commencement of baseline survey and final survey, researchers had obtained permission from headmasters in all participating schools, and written informed consent was sent to parents of each migrant child to explain the content of the survey. Each parent returned a consent form.

\section{Publisher's Note}

Springer Nature remains neutral with regard to jurisdictional claims in published maps and institutional affiliations.

Received: 7 September 2016 Accepted: 25 May 2017

Published online: 07 June 2017

\section{References}

1. National Bureau of Statistics of the People's Republic of China. The sixth national census data bulletin. National Bureau of Statistics of the People's Republic of China. Available at: http://www.stats.gov.cn/tjsj/pcsj/rkpc/6rp/ indexch.htm. Accessed 28 Apr 2011

2. The People's Government of Guangzhou Municipality. The Guangzhou Women's Development Plan (2011-2020) and the Guangzhou Children's Development Plan (2011-2020). Available at: http://zwgk.gz.gov.cn/GZ00/2. 3/201206/948218.shtml. Accessed 27 June 2012

3. Sheiham A. Dental caries affects body weight, growth and quality of life in pre-school children. Br Dent J. 2006;201(10):625-6.

4. Sun $\mathrm{X}$, Chen $\mathrm{M}$, Chan KL. A meta-analysis of the impacts of internal migration on child health outcomes in China. BMC Public Health. 2016;16(1):66.

5. Hu X, Cook S, Salazar MA. Internal migration and health in China. Lancet. 2008:372(9651):1717-9.

6. Hu DY, Hong X, Li X. Oral health in China-trends and challenges. Int J Oral Sci. 2011:3(1):7-12.

7. Wang HY, Petersen PE, Bian JY, Zhang BX. The second national survey of oral health status of children and adults in China. Int Dent J. 2002;52(4):283-90.

8. Gao J, Ruan J, Zhao L, Zhou H, Huang R, Tian J. Oral health status and oral health knowledge, attitudes and behavior among rural children in Shaanxi, western China: a cross-sectional survey. BMC Oral Health. 2014;14:144.

9. Gao XL, McGrath C, Lin HC. Oral health status of rural-urban migrant children in South China. Int J Paediatr Dent. 2011:21(1):58-67.

10. Miller $E$, Lee JY, DeWalt DA, Vann WJ. Impact of caregiver literacy on children's oral health outcomes. Pediatrics. 2010;126(1):107-14.

11. Parker EJ, Jamieson LM. Associations between indigenous Australian oral health literacy and self-reported oral health outcomes. BMC Oral Health. 2010;10:3.

12. Deinzer R, Micheelis W, Granrath N, Hoffmann T. More to learn about: periodontitis-related knowledge and its relationship with periodontal health behaviour. J Clin Periodontol. 2009;36(9):756-64.

13. Ji $Y$, Zhang $Y$, Wang $Y L$, Chang $C$. Association between family factors and children's oral health behaviors - a cross-sectional comparative study of permanent resident and migrant children in large cities in China. Community Dent Oral. 2016;44(1):92-100. 
14. Wong MC, Lo EC, Schwarz E, Zhang HG. Oral health status and oral health behaviors in Chinese Children. J Dent Res. 2001;80(5):1459-65.

15. O'Connell AA. Logistic Regression Models for Ordinal Response Variables. Thousand Oaks: SAGE Publications, Inc; 2006.

16. Burnett $D$, Aronson J, Asgary R. Oral health status, knowledge, attitudes and behaviours among marginalized children in Addis Ababa, Ethiopia. J Child Health Care. 2016;20(2):252-61.

17. Prasai DL, Shakya A, Shrestha M, Shrestha A. Dental caries prevalence, oral health knowledge and practice among indigenous Chepang school children of Nepal. BMC Oral Health. 2013;13:20.

18. Qi X. A report from 3rd national oral health epidemiologic survey. Beijing: People's Medical Publishing House; 2008.

19. Jurgensen N, Petersen PE. Oral health and the impact of socio-behavioura factors in a cross sectional survey of 12-year old school children in Laos. BMC Oral Health. 2009:9:29.

20. Folayan MO, Khami MR, Onyejaka N, Popoola BO, Adeyemo Yl. Preventive oral health practices of school pupils in Southern Nigeria. BMC Oral Health. 2014;14:83.

21. Smit DA, Naidoo S. Oral health effects, brushing habits and management of methamphetamine users for the general dental practitioner. Br Dent J. 2015, 218(9):531-6.

22. David J, Wang NJ, Astrom AN, Kuriakose S. Dental caries and associated factors in 12-year-old schoolchildren in Thiruvananthapuram, Kerala, India. Int J Paediatr Dent. 2005;15(6):420-8.

23. Shinga-Ishihara C, Nakai Y, Milgrom P, Murakami K, Matsumoto-Nakano M. Cross-cultural validity of a dietary questionnaire for studies of dental caries risk in Japanese. BMC Oral Health. 2014;14:1.

24. Skeie MS, Riordan PJ, Klock KS, Espelid I. Parental risk attitudes and cariesrelated behaviours among immigrant and western native children in Oslo. Community Dent Oral Epidemiol. 2006;34(2):103-13.

25. Petersen PE. Strengthening of oral health systems: oral health through primary health care. Med Princ Pract. 2014;23(Suppl 1):3-9.

26. Folayan MO, Kolawole KA, Oyedele T, Chukwumah NM, Onyejaka N, Agbaje $\mathrm{H}$, Oziegbe EO, Oshomoji OV. Association between knowledge of caries preventive practices, preventive oral health habits of parents and children and caries experience in children resident in sub-urban Nigeria. BMC Oral Health. 2014;14:156.

27. Zhang JJ, Li NX, Liu CJ. Associations between poor health and schoolrelated behavior problems at the child and family levels: a cross-sectional study of migrant children and adolescents in southwest urban China. J Sch Health. 2010;80(6):296-303.

28. Vilella KD, Alves SG, de Souza JF, Fraiz FC, Assuncao LR. The Association of Oral Health Literacy and Oral Health Knowledge with Social Determinants in Pregnant Brazilian Women. J Community Health. 2016;41(5):1027-32.

29. Baseer MA, Mehkari MA, Al-Marek FA, Bajahzar OA. Oral health knowledge, attitude, and self-care practices among pharmacists in Riyadh, Riyadh Province, Saudi Arabia. J Int Soc Prev Community Dent. 2016;6(2):134-41.

30. Mattila ML, Tolvanen M, Kivela J, Pienihakkinen K, Lahti S, Merne-Grafstrom M. Oral health-related knowledge, attitudes and habits in relation to perceived oral symptoms among 12-year-old school children. Acta Odontol Scand. 2016;74(5):343-7.

31. Wilson AR, Brega AG, Campagna EJ, Braun PA, Henderson WG, Bryant LL, Batliner TS, Quissell DO, Albino J. Validation and Impact of Caregivers' Oral Health Knowledge and Behavior on Children's Oral Health Status. Pediatr Dent. 2016;38(1):47-54.

32. ElKarmi R, Shore E, O Connell A. Knowledge and behaviour of parents in relation to the oral and dental health of children aged 4-6 years. Eur Arch Paediatr Dent. 2015;16(2):199-204.

\section{Submit your next manuscript to BioMed Central and we will help you at every step:}

- We accept pre-submission inquiries

- Our selector tool helps you to find the most relevant journal

- We provide round the clock customer support

- Convenient online submission

- Thorough peer review

- Inclusion in PubMed and all major indexing services

- Maximum visibility for your research

Submit your manuscript at www.biomedcentral.com/submit
Biomed Central 